\title{
Diet Induced Inflammation and Potential Consequences on Fetal Development
}

\section{Hemalatha $\mathbf{R}^{\star}$}

Clinical \& Microbiology Department, National Institute of Nutrition, ICMR, Hyderabad, 500007, India

\begin{abstract}
The significance of diet induced inflammation in gestational tissues (chorioamnionitis) on fetal growth and development is emerging as an important area of research. Role of infection and intrauterine inflammation in preterm deliveries has been extensively explored, but, implication of sterile inflammation (not associated with infection) on fetal development has received little attention. Inflammation is generally thought to be the result of a local or systemic infection or products of infection; conversely, inflammation may result from high calorie intake or from diets low in micronutrients. While systemic inflammation is widely proposed as the predisposing factor for the increasing incidence of non-communicable diseases such as diabetes mellitus and cardiovascular diseases in adults, accumulating evidences now suggest that low grade intrauterine inflammation might impair linear growth and adversely affect myogenesis and adipogenesis that might have lasting effects on offspring. Given that intrauterine inflammation is frequently present, its origin and impact on fetal development needs attention. The public health implications of nutrition-mediated inflammation is of particular importance in India, which is burdened with problem of over-nutrition coupled with undernutrition and micronutrient malnutrition. Studies to unearth the link between nutrition and inflammation and its impact on fetal growth and development are needed. This review explores the potential consequences of intrauterine inflammation on fetal growth and development.
\end{abstract}

Keywords: Inflammation; Chorioamnionitis; Nutrition; Fetal growth; Diabetes; Insulin resistance; Myogenesis; Adipogenesis

\section{Introduction}

The immune system is a complex array of organs, tissues and specialized cells that protects the body from outside invaders, such as bacteria, viruses, parasites and from other harmful invaders [1]. Inflammation is a nonspecific protective action of the immune system, a response that defends the host from bacteria and other infectious agents [2]. Typically, inflammation is the result of a highly nuanced interaction between pro- and anti-inflammatory cytokines, thought to originate only during infections $[3,4]$. Conversely, inflammation may result from high calorie intake or from diets low in micronutrients as well. High calorie diet is associated with exaggerated post-prandial spikes in glucose and lipids that generate excess free radicals that stimulate chronic low-grade systemic inflammation $[5,6]$.

High calorie and the ensuing chronic inflammatory state induce insulin resistance and is the underlying cause of many chronic diseases such as obesity, diabetes, atherosclerosis, cancer and arthritis [6-10]. Many age related diseases such as cataract and Alzheimer's disease are also attributed at least partially to inflammation.

Even as chronic low grade systemic inflammation is proposed as the predisposing factor in the increasing incidence of non-communicable diseases such as diabetes mellitus and cardiovascular diseases in adults $[11,12]$, recent observations have revealed that intrauterine inflammation, due to high calorie diet during pregnancy, may predispose the offspring to the adult chronic diseases. Inflammation due to high calorie diet during pregnancy has been shown to adversely influence myogenesis and triglyceridemia and adipose tissue deposition in muscle and liver of offspring [13-15]. Exposures, during critical periods of development are highly vulnerable to insults such as faulty diet, which may permanently alter myogenesis and adipogenesis potential in the offspring. In this connection, the role of nutrition and intrauterine inflammation in a particularly vulnerable subset of the population, that of undernourished women in the reproductive age, deserves to be critically examined [16-18].

\section{Nutrition and Systemic Inflammation}

It is now well accepted that low-grade chronic systemic inflammation also called sterile inflammation is associated with high calorie diet in the absence of any systemic or local infection and that inflammation contributes to risk of insulin resistance and related disorders [19-23]. High fat or high calorie diet associated with exaggerated post-prandial spikes in glucose and lipids generate excess free radicals that can trigger low-grade systemic inflammation [5,24]. Numerous studies have shown elevated concentration of adipose tissue derived cytokines in obese humans, suggesting a concept that inflammation may be derived from the accumulation of activated macrophages surrounding enlarged adipocytes in obese subjects [19-23]. Other studies have shown that circulating free fatty acids (FFA) can directly trigger inflammatory responses by activating toll like receptors (TLR)-4 or nuclear factor kappa b (NF-kB) [24-26]. Furthermore, accumulating pyruvate in mitochondria may favour free radical generation and inflammation during glucose metabolism [22]. Taken together, these studies suggest that inflammation can possibly occur after every high calorie meal, and that obesity is not a prerequisite.

In addition to the direct effect of FFA on inflammatory cascade, intake of a high calorie diet can alter gut bacteria and affect intestinal barrier function and favour endotoxemia and inflammation by a mechanism that increases intestinal permeability [26,27]. Thus indicating gastrointestinal tract as a potential source of inflammation associated with high calorie diet. High calorie diet is followed by

*Corresponding author: Hemalatha R, Department of Clinical \& Microbiology, National Institute of Nutrition, ICMR, Hyderabad, 500007, India, Tel: 040-27191297 Fax: 040-27019074; E-mail: rhemalathanin@yahoo.com

Received May 08, 2013; Accepted June 17, 2013; Published June 19, 2013

Citation: Hemalatha R (2013) Diet Induced Inflammation and Potential Consequences on Fetal Development. J Nutr Disorders Ther 3: 125. doi:10.4172/2161-0509.1000125

Copyright: (c) 2013 Hemalatha R. This is an open-access article distributed under the terms of the Creative Commons Attribution License, which permits unrestricted use, distribution, and reproduction in any medium, provided the original author and source are credited. 
reduction in gram positive bifidobacteria and increase in gram negative bacteria. With reduction in gram positive bacteria, the intestinal membrane integrity is impaired, which becomes more permeable to endotoxin (cell wall component of gram negative bacteria) resulting in increasing endotoxin (lipopolysaccharide (LPS) in the blood, which stimulates TLR-4 on immune cells and triggers systemic inflammation $[26,27]$. Alternatively, gut microbiota on a high-fat diet may convert dietary choline into methylamines, reducing choline bioavailability, which is necessary for the secretion of VLDLs. This may eventually promote fatty liver, insulin resistance and lipid peroxidation and inflammation [28].

In India, a large proportion of population is insulin resistant and the prevalence of diabetes and chronic heart disease (CHD) is high [29-31]. Though, it may be presumed that increasing prevalence of diabetes in Indians is due to lack of physical activity and excess calorie intake, the role of inflammation is not known. Excess calorie intake stimulates inflammatory cytokines, leading to insulin resistance and eventually to diabetes; consequently, it is plausible to believe that it is overnutrition or faulty nutrition (diet that is poor in micronutrients) that are responsible for inflammation, insulin resistance and associated disorders, rather than high fat or high carbohydrate diets [29-31]. A link between obesity and insulin resistance is well known, but a significant proportion of population with insulin resistance in India are not obese, but are centrally adipose [32-34]. Indians are susceptible to diabetes at a younger age and at a relatively lower BMI compared to the whites, but the thin Indians have higher body fat percent, especially visceral adiposity $[33,34]$. Though, evidence linking thin fat babies and susceptibility to metabolic syndrome like characteristics is overwhelming, inflammation as the cause for adipogenesis in foetal life is inconclusive [33,34].

\section{Inflammation in Gestational Membranes (chorioam- nionitis) and Offspring Phenotype}

Studies on Indian neonates showed higher insulin levels and greater adiposity even at birth compared to Caucasians [33,34]. They also showed low birth weight as contributing factor to insulin resistance among Indians [33]. The hypothesis is that, small Indian babies have smaller abdominal viscera and low muscle mass, but preserve body fat during their intrauterine development, which may predispose to an insulin-resistant state [34]. Though mechanism for thin-fat Indian body composition related to fat and muscle components is not known, it may be presumed that intrauterine epigenetic regulation perhaps mediated by intrauterine inflammation could contribute to less skeletal muscle and more fat mass formation; however, we need to confirm this hypothesis as also the burden and origin of intrauterine inflammation in India.

The foetal stage is critical for skeletal muscle and adipose tissue development. Skeletal muscle forms 40 to $50 \%$ of total body mass composition [35]. Fetal stage contains a large number of mesenchymal stem cells (MSC) that differentiate into the myogenic cells, adipogenic cells and fibrogenic cells around mid-gestation. Differentiation of MSC is controlled by a set of transcription factors, which Include wingless and int (WNT), paired box gene 3 (PAX3), (PAX7) and myogenic regulatory factors [35-37]. Activation of the WNT signaling pathway leads to the transformation of nonmyogenic cells into the myogenic lineage and suppression of MSC commitment to the adipogenic lineage $[38,39]$. MSC committed to become myogenic progenitor cells express PAX 3 and PAX7, which then induce MRF [40]. Under the control of MRFs myogenic precursors cells differentiate into myoblasts and then myotubes; however, proinflammatory cytokines in the gestational tissues inhibits skeletal myogenesis through transcriptional silencing of myofibrillar genes $[14,13]$. Skeletal muscle develops during embryonic, fetal and postnatal period. Most muscle fibres develop during fetal stage and therefore this stage is critial for skeletal muscle formation [34-36].

Foetal inflammation has been shown to impair foetal skeletal muscle development while promoting adipogenesis [40,13,41]. Inflammation due to any stress might influence myogenesis through activation of NF- $\kappa \mathrm{B}$, which is upregulated during adipogenesis and fat cell differentiation [42]. In contrast, inhibition of NF- $\kappa \mathrm{B}$ and TNF $\alpha$ are associated with expression of myogenic genes. The potential role of inflammation in MSC differentiation was further evidenced by c-Jun $\mathrm{N}$-terminal kinases (JNK) signaling. The absence of JNK has been reported to decrease adipogenesis $[43,44]$. Accordingly, inflammation increases intramuscular fat and connective tissue deposition and reduces number of muscle fiber and/or diameter with adverse consequences in adult life [45-48]. Adipocytes arise from MSCs during mid to late gestation. Thus, any insult such as maternal undernutrition, overnutrition or infection, occurring during mid-gestation, can induce inflammation and may shift MSC from myogenesis to adipogenesis or fibrogenesis [45-47].

Skeletal muscle and liver are the organs critical for glucose metabolism [49]. Skeletal muscle is the key organ for glucose and fatty acid utilization [50]. Poor skeletal muscle development impairs glucose and fatty acid metabolism and predisposes offspring to diabetes and obesity. Linkage between maternal intake or nutritional status and chronic noncommunicable diseases in the offspring through an inflammatory path way is still under exploratory stage. Nevertheless, it is important to understand the source (diet and infection) and the role of inflammation on fetal muscle and fat development and higher diabetes and cardiovascular risk of thin fat Indian babies. Especially, when, higher diabetes and cardiovascular risk in thin fat Indian babies, who are overweight/obese at later stage has been suggested to be an inevitable consequence of socioeconomic development [51].

\section{Maternal Nutrition and Inflammation in Gestational Membranes (Chorioamnionitis)}

It is rather well established that perinatal undernutrition and reduced birth weight result in offspring phenotype that has increased risk of coronary heart disease, diabetes, hypertension and stroke in adulthood [48]. But, overnutrition associated with Inflammation in gestational membranes can promote a similar phenotype that has increased risk of coronary heart disease, diabetes, hypertension and stroke in adulthood is a relatively recent concept. Studies have demonstrated the relation between maternal over nutrition and increased risk of cardiovascular or diabetes type 2 phenotype of the offspring [35,52]. A cohort study from Scotland suggested programming of blood pressure and glucose metabolism in adult offspring of women who consumed high carbohydrate diet $[52,53]$. Similarly, children born to mothers on high fat diet (HFD) had accelerated development of fatty streaks in aorta $[54,55]$.

The adverse effects of maternal overnutrition have been shown to be mediated through chronic low grade inflammation in gestational tissues (intrauterine inflammation) (Figure 1). Consumption of a HFD increases placental inflammatory cytokines and the expression of toll-like receptor [56]. The extent to which maternal undernutrition (particularly micronutrient malnutrition), which is widely prevalent in India, could influence immuno-modulatory functions and then induce inflammation in gestational membranes is not known [57]. Earlier, 
Citation: Hemalatha R (2013) Diet Induced Inflammation and Potential Consequences on Fetal Development. J Nutr Disorders Ther 3: 125. doi:10.4172/2161-0509.1000125

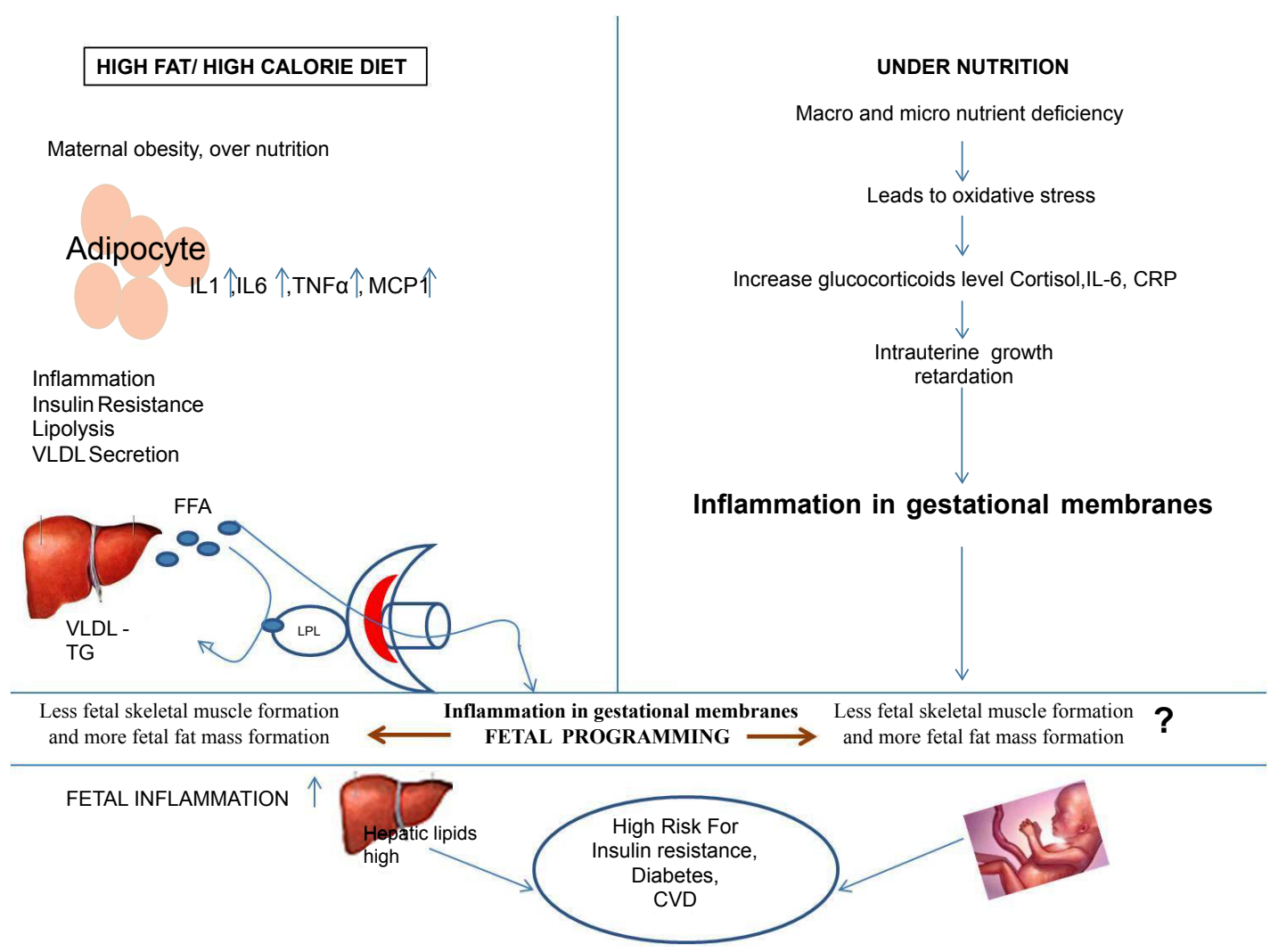

Figure 1: Suboptimal or excess nutrition in pregnancy induce inflammatory responses in the gestational (fetal) membranes that may promote less skeletal mass and more fat mass formation in the offspring; eventually predisposing the offspring to high risk for insulin resistance, diabetes, cardiovascular diseases (CVD) at later stage in life.

LPL (Placental Lipoprotein Lipase); MCP1 (Monocyte Chemoatractant Protein 1)

a study at National Institute of Nutrition (NIN) found histologic chorioamnionitis (intrauterine inflammation) associated with high concentration of interleukin 8 (IL-8) and interleukin 6 (IL-6) in chorioamnion membranes of twenty nine percent of apparently normal women who were undernourished. Most of the women with histologic chorioamnionitis had foetal growth restriction [16]. Studies conducted at NIN, suggest that nearly $29 \%$ and $30 \%$ of randomly selected, apparently normal, free living pregnant or nonpregnant population in India, have intrauterine or cervico vaginal inflammation respectively $[16,17]$. Importantly, 30\% of both pregnant and nonpregnant population were undernourished and Vitamin A deficiency was significantly associated with cervico vaginal inflammation. Heightened local inflammation is often associated with abnormal local (vaginal) flora as well [17]. It is evident from these observations that any form of malnutrition such as overnutrition or undernutrition, micronutrient deficiency may potentially induce intrauterine inflammation in gestational membranes (Figure 1). Additionally, infections during pregnancy, which stimulate inflammation, may also have a role. It is seemingly possible that maternal malnutrition and infections may share many of the same adverse consequences and reflect two sides of the same coin (Figure 1). In both cases, alterations in physiological functions can be induced and may lead to the development of a phenotype that increases the susceptibility to non-communicable conditions.

In summary, exposure to high-fat diets or to undernutrition in utero might program the offspring to intrinsic enhanced lipogenesis and adipocyte proliferation. This is attributed to inflammation and early induction of adipogenic transcription factor peroxisome proliferatoractivated receptor (PPAR) $\gamma$, whose activity is enhanced with excess nutriton or undernutrition. Induction of adipogenic transcription factor peroxisome proliferator-activated receptor (PPAR) $\gamma$ activity is enhanced under limited or excess nutrient availability. Nonetheless, this occurs via different mechanisms involving PPAR $\gamma$ coregulators: in undernutrition, it is upregulation of coactivators, whereas in excess nutriton, it is downregulation of corepressors [58-60].

Though, evidence of diet induced inflammation and altered foetal phenotype is overwhelming, the data are inconclusive. How far, the association between nutrition and inflammation can be extended to thin fat phenotype of Indians, needs to be investigated. In Indian context, where both overnutrition and undernutrition are widely prevalent, it becomes that much more important to address the issue of causal relationship of diet and intrauterine inflammation.

\section{Other Well Known Complications of Inflammation (Chorioamnionitis)}

Reproductive tract inflammation has been widely implicated in preterm delivery (PTD), intrauterine growth restriction (IUGR), increased HIV and sexually transmissible infections (STIs) and HIV replication [61-64]. Evidence for fetal involvement with funisitis and chorionic vasculitis has been reported in chorioamnionitis $[65,66]$ Histologic chorioamnionitis (HCA) and fetal inflammatory response (FIR) have been reported to be associated with IUGR, with extremely 
low gestational age at birth [62]. Around 90\% of all LBW infants are born in developing countries, which are caused by IUGR rather than PTD, most of which, may be mediated by inflammation $[67,68]$.

In ourstudy, babiesborn to mothers with histologicchorioamnionitis (HCA), also called intrauterine inflammation, weighed $140 \mathrm{~g}$ lesser and were $1.2 \mathrm{~cm}$ shorter [16]. The birth weight, crown-heel length and head circumference of these babies were consistently lower than babies born to mothers without HCA. Furthermore, it was interesting to note that higher proportion of mothers who delivered babies with symmetrical growth restriction (SGR) had histologic chorioamnionitis, suggesting the possibility of histologic chorioamnionitis right from early pregnancy $[16,68]$. Moreover, concentration of IL8 in our women was considerably higher than that reported elsewhere [69].

Similar results were reported by Williams etal. who defined histologic chorioamnionitis as marked leukocyte infiltrate of placenta and showed association of HCA with markers of fetal growth restriction (birth weight, length, head circumference, weight/length ratio and Ponderal index in the lowest $5^{\text {th }}$ percentile) $[16,63]$. Taken together, these results suggest that evidence linking role of inflammation (chorioamnionitis) and foetal growth restriction and development is scanty, though its link with preterm delivery is relatively well established. In India, foetal growth restriction and preterm delivery contribute to 20 and $10 \%$ of low birth weight (LBW) respectively. Yet, role of inflammation (chorioamnionitis) on LBW is scant [16]. Understanding burden of inflammation and its role on foetal growth and development could be very important in India to prevent immediate (preterm and LBW) as well as long term complications (NCD)

\section{Inflammation in the Gestational Membranes (Chorio- amnionitis) due to Infections}

Intrauterine inflammation is defined as the presence of inflammatory infiltrates in the chorion, amnion, or decidua and has been suggested as a good marker for intrauterine infection [70-72]. Chorioamnionitis or intra-amniotic infection is an inflammation of placenta membranes, typically caused by bacteria ascending from lower genital tract.

Extension of inflammation to the chorionic plate and umbilical cord and to the fetal vessels is termed foetal inflammatory response (FIR) [65,66]. Chorioamnionitis is often due to a polymicrobial infection caused by organisms ascending from lower genital tract [70,71]. Ureaplasma urealyticum and Mycoplasma hominis, which are commonly found in the lower genital tract, constitute the most frequently isolated organisms from chorioamnion inflammation $[62,64,71]$. Anaerobes such as Gardnerella vaginalis (25\%) and bacteroides (30\%), as well as aerobes such as Group B streptococcus (15\%) and gram-negative rods including Escherichia coli (8\%) [72,73] are also isolated frequently from chorioamnion inflammation. Chorioamnionitis due to hematogenous spread is relatively rare, but may occur in women with perionditis or some viral infections. Human case-control studies have demonstrated that women who have low-birth-weight infants as a consequence of either preterm labor or premature rupture of membranes tend to have more severe periodontal disease than mothers with normal-birth-weight infants [74], suggesting that a remote infection such as periodontal disease may have the potential to affect pregnancy outcome by triggering inflammation in placental membranes with histologically proven chorioamnionitis in the absence of any bacterial infection in the vagina or cervical area [74]. It is well known that local or remote infection may induce inflammation, but, it would be important to investigate the consequences of infection induced inflammation and influence on myogenensis and adipogenesis in the offspring.

\section{Conclusions}

In summary, faulty maternal nutrition stimulates inflammation and promotes a phenotype that is more susceptible to metabolic syndrome like characteristics. Though, evidence pointing to the association between inflammation and genes regulating fetal myogenesis and adipogenesis is overwhelming; evidence is lacking with respect to type of maternal nutrition and inflammation, barring a few studies linking maternal obesity and high fat diet and intrauterine inflammation. Subclinical intrauterine inflammation appears to be more common than anticipated in pregnant women. Detailed investigations as to the type of diet (high/low calorie/micronutrient malnutrition) in pregnancy that induces chronic local inflammation are required to fill the gaps in our knowledge to enable us to move closer towards providing meaningful diet advice to pregnant women. Given the prevalence of adolescent female undernutrition in India, such studies take on more relevance.

\section{References}

1. Mackan IR, Rosen FS (2001) Advances in immunology. N Engl J Med 344 350-362.

2. Bottomly K (1988) A functional dichotomy in CD4+ T lymphocytes. Immunol Today 9: 268-274.

3. Elenkov IJ, Chrousos GP (1999) Stress Hormones, Th1/Th2 patterns, Pro/ Anti-inflammatory Cytokines and Susceptibility to Disease. Trends Endocrinol Metab 10: 359-368.

4. Marín-Corral J, Martínez-Caro L, Lorente JA, de Paula M, Pijuan L, et al. (2010) Redox balance and cellular inflammation in the diaphragm, limb muscles, and lungs of mechanically ventilated rats. Anesthesiology 112: 384-394.

5. Galland L (2010) Diet and inflammation. Nutr Clin Pract 25: 634-640.

6. Esposito K, Giugliano D (2006) Diet and inflammation: a link to metabolic and cardiovascular diseases. Eur Heart J 27: 15-20.

7. Paz K, Hemi R, LeRoith D, Karasik A, Elhanany E et al. (1997) A molecular basis for insulin resistance. Elevated serine/threonine phosphorylation of IRS-1 and IRS-2 inhibits their binding to the juxtamembrane region of the insulin recepto and impairs their ability to undergo insulin-induced tyrosine phosphorylation. $J$ Biol Chem $272: 29911-29918$

8. Nayak BS, Lesley R (2006) Relationship between inflammatory markers, metabolic and anthropometric variables in the Caribbean type 2 diabetic patients with and without microvascular complications. Journal of Inflammation 3:17.

9. Chan MM, Moore AR (2010) Resolution of inflammation in murine autoimmune arthritis is disrupted by cyclooxygenase-2 inhibition and restored by prostaglandin E2-mediated lipoxin A4 production. J Immunol 184: 6418-6426.

10. Coussens LM, Werb Z (2002) Inflammation and cancer. Nature 420: 860-867.

11. Shoelson SE, Herrero L, Naaz A (2007) Obesity, inflammation, and insulin resistance. Gastroenterology 132: 2169-2180.

12. Galic S, Oakhill JS, Steinberg GR (2010) Adipose tissue as an endocrine organ. Mol Cell Endocrinol 316: 129-139.

13. Wang H, Hertlein E, Bakkar N, Sun H, Acharyya S, et al. (2007) NF-kappaB regulation of $Y Y 1$ inhibits skeletal myogenesis through transcriptional silencing of myofibrillar genes. Mol Cell Biol 27: 4374-4387.

14. Langen RC, Van Der Velden JL, Schols AM, Kelders MC, Wouters EF, et al (2004) Tumor necrosis factor-alpha inhibits myogenic differentiation through MyoD protein destabilization. FASEB J 18: 227-237.

15. Aagaard-Tillery KM, Grove K, Bishop J, Ke X, Fu Q, et al. (2008) Developmenta origins of disease and determinants of chromatin structure: maternal diet modifies the primate fetal epigenome. J Mol Endocrinol 41: 91-102.

16. Hemalatha R, Ramalaxmi BA, Quadri SSYH, Annapurna VV, Balakrishna $\mathrm{N}$ et al.(2008) Intrauterine growth restriction in term women with Histologic 
Citation: Hemalatha R (2013) Diet Induced Inflammation and Potential Consequences on Fetal Development. J Nutr Disorders Ther 3: 125. doi:10.4172/2161-0509.1000125

chorioamnionitis. Research Journal of Obstetric and Gynecoloy 1: 18-24.

17. Hemalatha R, Ramalakshmi BA, Krishna Swetha G, Uday Kumar P, Madhusudhan Rao D et al. (2012) Cervicovaginal inflammatory cytokines and sphingomyelinase in women with and without bacterial vaginosis. Am. J of Med Sci 344: 35-39.

18. Lee DE, Kehlenbrink S, Lee H, Hawkins M, Yudkin JS (2009) Getting the message across: mechanisms of physiological cross talk by adipose tissue. Am J Physiol Endocrinol Metab 296: E1210-1229.

19. Greenberg AS, Obin MS (2006) Obesity and the role of adipose tissue in inflammation and metabolism. Am J Clin Nutr 83: 461S-465S.

20. Kern PA, Ranganathan S, Li C, Wood L, Ranganathan G (2001) Adipose tissue tumor necrosis factor and interleukin- 6 expression in human obesity and insulin resistance. Am J Physiol Endocrinol Metab 280: E745-751.

21. Schenk S, Saberi M, Olefsky JM (2008) Insulin sensitivity: modulation by nutrients and inflammation. J Clin Invest 118: 2992-3002.

22. Kennedy A, Martinez K, Chuang CC, LaPoint K, McIntosh M (2009) Saturated fatty acid-mediated inflammation and insulin resistance in adipose tissue: mechanisms of action and implications. J Nutr 139: 1-4

23. Margioris AN (2009) Fatty acids and postprandial inflammation. Curr Opin Clin Nutr Metab Care 12: 129-137.

24. Esposito K, Nappo F, Marfella R, Giugliano G, Giugliano F, et al. (2002) Inflammatory cytokine concentrations are acutely increased by hyperglycemia in humans: role of oxidative stress. Circulation 106: 2067-2072.

25. Ceriello A, Taboga C, Tonutti L, Quagliaro L, Piconi L, et al. (2002) Evidence for an independent and cumulative effect of postprandial hypertriglyceridemia and hyperglycemia on endothelial dysfunction and oxidative stress generation: effects of short- and long-term simvastatin treatment. Circulation 106: 1211 1218.

26. Cani PD, Amar J, Iglesias MA, Poggi M, Knauf C, et al. (2007) Metabolic endotoxemia initiates obesity and insulin resistance. Diabetes 56: 1761-1772.

27. Cani PD, Bibiloni R, Knauf C, Waget A, Neyrinck AM, et al. (2008) Changes in gut microbiota control metabolic endotoxemia-induced inflammation in high-fat diet-induced obesity and diabetes in mice. Diabetes 57: 1470-1481.

28. Dumas ME, Barton RH, Toye A, Cloarec O, Blancher C, et al. (2006) Metabolic profiling reveals a contribution of gut microbiota to fatty liver phenotype in insulin-resistant mice. Proc Natl Acad Sci U S A 103: 12511-12516.

29. Fall CH, Stein CE, Kumaran K, Cox V, Osmond C, et al. (1998) Size at birth, maternal weight, and type 2 diabetes in South India. Diabet Med 15: 220-227.

30. Gupta R, Gupta VP (1996) Meta-analysis of coronary heart disease prevalence in India. Indian Heart J 48: 241-245.

31. Misra A, Chaudhary D, Vikram NK, Mittal V, Devi JR, et al. (2002) Insulin resistance and clustering of atherogenic risk factors in women belonging to low socio-economic strata in urban slums of North India. Diabetes Res Clin Pract 56: 73-75.

32. Hemalatha R, Annapurna VV, Damayanthi K, Radhakrishna KV (2010) Substantial proportion of apparently healthy urban South Indian young adults has Insulin Resistance associated with other cardiovascular risk factors. Journal of Medical Sciences 3: 110-117.

33. Yajnik CS, Fall CH, Coyaji KJ, Hirve SS, Rao S, et al. (2003) Neonatal anthropometry: the thin-fat Indian baby. The Pune Maternal Nutrition Study. Int J Obes Relat Metab Disord 27: 173-180.

34. Yajnik CS, Lubree HG, Rege SS, Naik SS, Deshpande JA, et al. (2002) Adiposity and hyperinsulinemia in Indians are present at birth. J Clin Endocrinol Metab 87: 5575-5580.

35. Du M, Yan X, Tong JF, Zhao J, Zhu MJ (2010) Maternal obesity, inflammation, and fetal skeletal muscle development. Biol Reprod 82: 4-12.

36. Fehrer C, Lepperdinger G (2005) Mesenchymal stem cell aging. Exp Gerontol 40: $926-930$

37. Westerweel PE, Verhaar MC (2008) Directing myogenic mesenchymal stem cell differentiation. Circ Res 103: 560-561.

38. Polesskaya A, Seale P, Rudnicki MA (2003) Wnt signaling induces the myogenic specification of resident CD45+ adult stem cells during muscle regeneration. Cell 113: 841-852.
39. Otto A, Schmidt C, Luke G, Allen S, Valasek P, et al. (2008) Canonical Wnt signalling induces satellite-cell proliferation during adult skeletal muscle regeneration. J Cell Sci 121: 2939-2950.

40. Maroto M, Reshef R, Münsterberg AE, Koester S, Goulding M, et al. (1997) Ectopic Pax-3 activates MyoD and Myf-5 expression in embryonic mesoderm and neural tissue. Cell 89: 139-148.

41. Berg AH, Lin Y, Lisanti MP, Scherer PE (2004) Adipocyte differentiation induces dynamic changes in NF-kappaB expression and activity. Am J Physio Endocrinol Metab 287: E1178-1188.

42. Ardite E, Barbera JA, Roca J, Fernández-Checa JC (2004) Glutathion depletion impairs myogenic differentiation of murine skeletal muscle $\mathrm{C} 2 \mathrm{C} 12$ cells through sustained NF-kappaB activation. Am J Pathol 165: 719-728.

43. Strle K, Broussard SR, McCusker RH, Shen WH, LeCleir JM, et al. (2006) $\mathrm{C}$-jun $\mathrm{N}$-terminal kinase mediates tumor necrosis factor-alpha suppression of differentiation in myoblasts. Endocrinology 147: 4363-4373.

44. Trouche D, Grigoriev M, Lenormand JL, Robin P, Leibovitch SA, et al. (1993) Repression of c-fos promoter by MyoD on muscle cell differentiation. Nature 363: 79-82.

45. Bayol SA, Simbi BH, Bertrand JA, Stickland NC (2008) Offspring from mothers fed a 'junk food' diet in pregnancy and lactation exhibit exacerbated adiposity that is more pronounced in females. J Physiol 586: 3219-3230.

46. Stein CE, Fall CH, Kumaran K, Osmond C, Cox V, et al. (1996) Fetal growth and coronary heart disease in south India. Lancet 348: 1269-1273.

47. Newsome CA, Shiell AW, Fall CH, Phillips DI, Shier R, et al. (2003) Is birth weight related to later glucose and insulin metabolism?--A systematic review. Diabet Med 20: 339-348.

48. Barker DJ, Martyn CN, Osmond C, Wield GA (1995) Abnormal liver growth in utero and death from coronary heart disease. BMJ 310: 703-704.

49. Zambrano E, Martínez-Samayoa PM, Bautista CJ, Deás M, Guillén L, et al. (2005) Sex differences in transgenerational alterations of growth and metabolism in progeny (F2) of female offspring (F1) of rats fed a low protein diet during pregnancy and lactation. J Physiol 566: 225-236.

50. Zhao B, Wall RJ, Yang J (2005) Transgenic expression of myostatin propeptide prevents diet-induced obesity and insulin resistance. Biochem Biophys Res Commun 337: 248-255.

51. Bavdekar A, Yajnik C S, Fall C HD, Bapat S, Pandit AN, et al. (1999) Insulin Resistance Syndrome in 8 year old Indian children, Small at Birth, Big at 8 Years, or Both? Diabetes 48: 2422-29.

52. Campbell DM, Hall MH, Barker DJ, Cross J, Shiell AW, et al. (1996) Die in pregnancy and the offspring's blood pressure 40 years later. $\mathrm{Br} \mathrm{J}$ Obstet Gynaecol 103: 273-280.

53. Shiell AW, Campbell DM, Hall MH, Barker DJ (2000) Diet in late pregnancy and glucose-insulin metabolism of the offspring 40 years later. BJOG 107: 890-895

54. Napoli C, D'Armiento FP, Mancini FP, Postiglione A, Witztum JL et al. (1997) Fatty streak formation occurs in human fetal aortas and is greatly enhanced by maternal hypercholesterolemia. Intimal accumulation of low density lipoprotein and its oxidation precede monocyte recruitment into early atherosclerotic lesions. J Clin Invest $100: 2680-2690$.

55. Napoli C, Glass CK, Witztum JL, Deutsch R, D'Armiento FP, et al. (1999) Influence of maternal hypercholesterolaemia during pregnancy on progression of early atherosclerotic lesions in childhood: Fate of Early Lesions in Children (FELIC) study. Lancet 354: 1234-1241.

56. Frias AE, Morgan TK, Evans AE, Rasanen J, Oh KY, et al. (2011) Maternal highfat diet disturbs uteroplacental hemodynamics and increases the frequency of stillbirth in a nonhuman primate model of excess nutrition. Endocrinology 152 : 2456-2464.

57. Bhaskaram P, Hemalatha R, Narayana Goud B (2003) Expression of messenger ribonucleic acid and production of cytokines in children with malnutrition. Nutrition Research 23: 367-376.

58. Magee TR, Han G, Cherian B, Khorram O, Ross MG (2008) Down-regulation of transcription factor peroxisome proliferator-activated receptor in programmed hepatic lipid dysregulation and inflammation in intrauterine growth-restricted offspring. Am J Obstet Gynecol 199: 271.

59. Luzzo KM, Wang Q, Purcell SH, Chi M, Jimenez PT, et al. (2012) High fat die induced developmental defects in the mouse: oocyte meiotic aneuploidy and fetal growth retardation/brain defects. PLoS One 7: e49217. 
Citation: Hemalatha R (2013) Diet Induced Inflammation and Potential Consequences on Fetal Development. J Nutr Disorders Ther 3: 125. doi:10.4172/2161-0509.1000125

60. Howie GJ, Sloboda DM, Kamal T, Vickers MH (2009) Maternal nutritional history predicts obesity in adult offspring independent of postnatal diet. $J$ Physiol 587: 905-915.

61. Hillier SL, Martius J, Krohn M, Kiviat N, Holmes KK, et al. (1988) A case-contro study of chorioamnionic infection and histologic chorioamnionitis in prematurity. N Engl J Med 319: 972-978.

62. Witt A, Berger A, Gruber CJ, Petricevic L, Apfalter P, et al. (2005) Increased intrauterine frequency of Ureaplasma urealyticum in women with preterm labor and preterm premature rupture of the membranes and subsequent cesarean delivery. Am J Obstet Gynecol. 193:1663-1669.

63. Williams MC, O'Brien WF, Nelson RN, Spellacy WN (2000) Histologic chorioamnionitis is associated with fetal growth restriction in term and preterm infants. Am J Obstet Gynecol 183: 1094-1099.

64. Hillier S, Homes KK(1990) Bacterial vaginosis. In: Holmes KK, Mardh P-A sparling PF, et al. Editors. Sexually transmitted diseases. 2nd ed. New York: Mc Graw-Hill.

65. Chaiworapongsa T, Romero R, Kim JC, Kim YM, Blackwell SC, et al. (2002) Evidence for fetal involvement in the pathologic process of clinical chorioamnionitis. Am J Obstet Gynecol 186: 1178-1182.

66. Pacora P, Chaiworapongsa T, Maymon E, Kim YM, Gomez R, et al. (2002) Funisitis and chorionic vasculitis: the histological counterpart of the fetal inflammatory response syndrome. J Matern Fetal Neonatal Med 11: 18-25.

67. Ramakrishnan $U$ (2004) Nutrition and low birth weight: from research to practice. Am J Clin Nutr 79: 17-21.
68. Moormann AM, Sullivan AD, Rochford RA, Chensue SW, Bock PJ et al. (1999) Malaria and pregnancy: placental cytokine expression and its relationship to intrauterine growth retardation. J Infect Dis 180: 1987-1993.

69. Keelan JA, Marvin KW, Sato TA, Coleman M, McCowan LM, et al. (1999) Cytokine abundance in placental tissues: evidence of inflammatory activation in gestational membranes with term and preterm parturition. Am J Obstet Gynecol 181: $1530-1536$

70. Mi Lee S, Romero R, Lee KA, Jin Yang H, Joon Oh K, et al. (2011) The frequency and risk factors of funisitis and histologic chorioamnionitis in pregnant women at term who delivered after the spontaneous onset of labor. J Matern Fetal Neonatal Med 24: 37-42.

71. Yoon BH, Romero R, Park JS, Chang JW, Kim YA, et al. (1998) Microbia invasion of the amniotic cavity with Ureaplasma urealyticum is associated with a robust host response in fetal, amniotic, and maternal compartments. Am J Obstet Gynecol 179: 1254-1260.

72. Choudhury MR, Mathai M, Mathai E, Sridharan G, Jasper MP, et al. (1994) Prevalence of genital mycoplasma \& ureaplasma infections in pregnancy \& their effect on pregnancy outcome. Indian J Med Res 100: 15-18.

73. Tita AT, Andrews WW (2010) Diagnosis and management of clinical chorioamnionitis. Clin Perinatol 37: 339-354.

74. Offenbacher S, Katz V, Fertik G, Collins J, Boyd D, et al. (1996) Periodontal infection as a possible risk factor for preterm low birth weight. J Periodontol 67 1103-1113.
This article was originally published in a special issue, Diet \& Metabolic Disorders handled by Editor(s). Dr. Vera P Simovska, University of Bitola, Macedonia, The Former Yugoslav Republic Of 